\title{
Using LibGuides for an information literacy tutorial
}

Tutorial 2.0

O ne way librarians have worked to improve students' information literacy (IL) has been through the implementation of a credit course in IL. While this can be a viable option, the workload of designing and developing the course can be great in comparison to the number of students taking the course. As a result, many librarians have seen the advantages to crafting tutorials that students may use on demand. Beginning in 1999, the University of Texas Libraries offered the ambitious and innovative TILT (Texas Information Literacy Tutorial). With its lighthearted but effective treatment of content, rich media appeal, and strict adherence to the ACRL "Information Literacy Competency Standards for Higher Education," TILT found success through its comprehensive modular approach. Other academic libraries soon directed their students to TILT or devised their own tutorials for the sake of imparting local information (physical locations of collections and other resources within a building) and for building brand recognition.

Like other academic libraries, we at Bloomsburg University of Pennsylvania have used a variety of ways to teach IL. In addition to "one-shot" sessions, we have used a brief General Library Research Tutorial with freshmen to introduce them to the library and offered a onecredit online "Introduction to Library Research" course. This course, designed for undergraduate students by librarian Michael Coffta with the help of a library intern, was developed and taught using the Blackboard course management system. While the course received positive comments from students, after five years it needed to be revamped. At the same time, the General Library Research Tutorial available on the library's homepage did not cover all of the topics students needed to know — even though classroom professors tended to assume it did.

After much discussion, we decided to put the course on hiatus and to transfer as much course content as possible onto the library's Web site in new, independent tutorial modules that could be accessed by anyone at any time. We didn't want to "reinvent the wheel" and create a new tutorial from scratch, especially as we needed to complete the work in one summer, yet we needed a tutorial that would be specific to our library and that would incorporate some of the content from the one-credit course.

In other words, we needed a resource that would allow us to quickly brand existing content. LibGuides turned out to be the perfect tool to do that.

\section{Why LibGuides?}

It was fortuitous that while the tutorial development team (composed of four reference librarians and the government documents librarian) was debating how to create a tutorial,

Kathryn Yelinek is government documents librarian, interim English and Social Sciences librarian, e-mail: kyelinek@bloomu.edu; Linda Neyer is health sciences and sciences librarian, e-mail: Ineyer@bloomu.edu; Darla Bressler is education librarian, e-mail: dbressle@ bloomu.edu; Michael Coffta is business librarian, e-mail: mcoffta@bloomu.edu; and David Magolis is interim library director at Bloomsburg University of Pennsylvania, e-mail:dmagolis@bloomu.edu

๑ 2010 Kathryn Yelinek, Linda Neyer, Darla Bressler, Michael Coffta, and David Magolis 
the library's homepage was redesigned as a LibGuides page. LibGuides is an easy-to-use, Web 2.0 information management and Web publishing system that does not require a high level of technology expertise to create Web pages. It combines Web development tools, such as HTML editing software with wikis, blogs, RSS feeds, Web-based videos, and other social networking tools, into one package designed specifically for librarians with or without Web design expertise.

The library experimented first with LibGuides on a trial basis due to a consortia agreement. The librarians noted how easy the was easily maintained and updated and that had a user-friendly interface. It would require less time spent dealing with server uploads and downloads, staying current with software updates, gaining access to the Web page from anywhere to make changes, and enabling other library staff members to access the page to make updates.

Also, adding Web 2.0 content was simple. All of these characteristics made LibGuides exactly what we were looking for in a new Web site. It also made LibGuides a good choice for the new online information literacy tutorial.

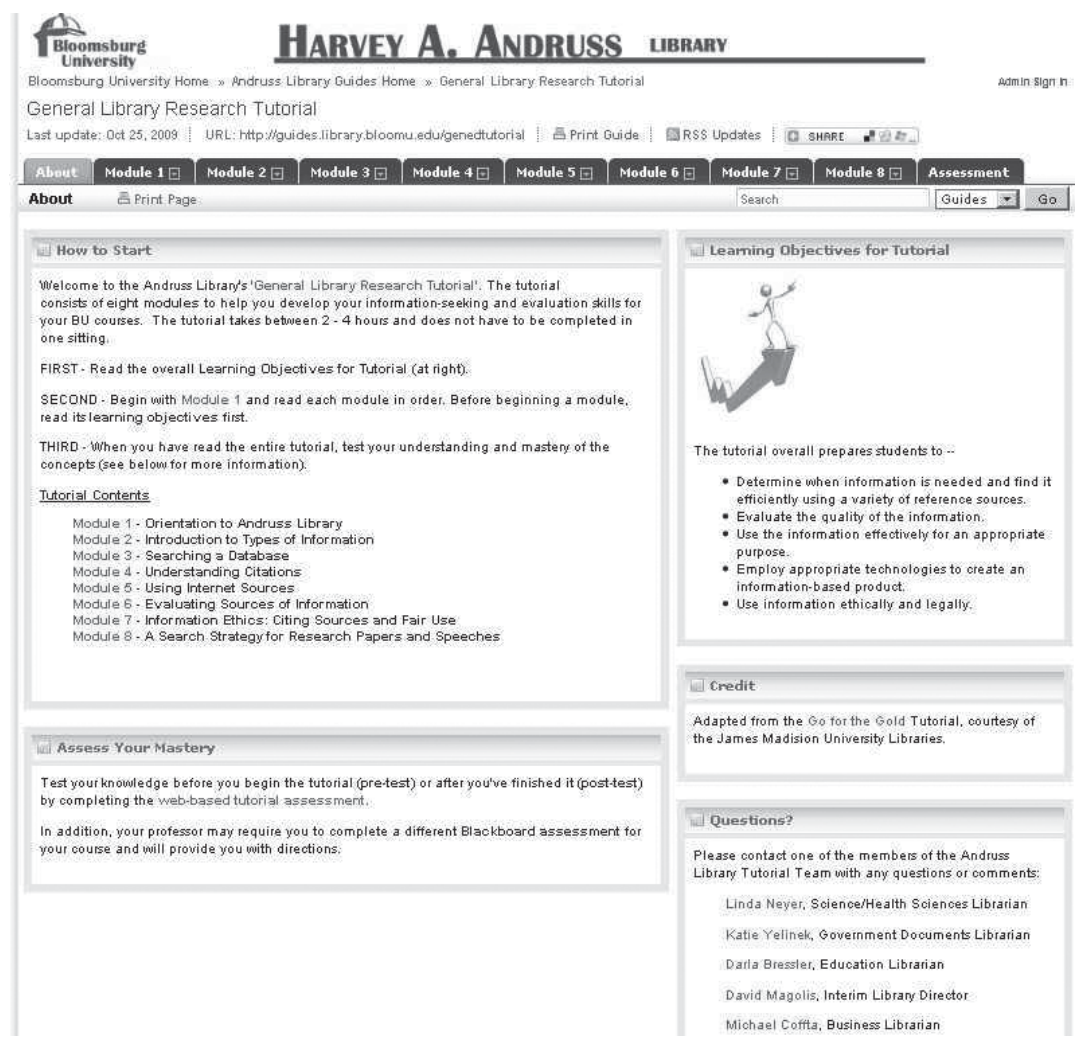

software was to use; ideas started to snowball, and other pages were quickly created.

After the Pennsylvania State System of Higher Education Keystone Library Network made the decision to license LibGuides, our Webmaster, David Magolis, decided that using LibGuides for the library's homepage would meet the needs for a new library page that

\section{"Go For the Gold" tutorial}

Once we chose the software, we needed to decide on content. One librarian on the team, Linda Neyer, was familiar with the work of librarians at James Madison University (JMU) described in an article published in May 2007 in College \& Research Libraries. ${ }^{1}$ Since 1999, JMU has required freshmen to take an 
Information-Seeking Skills Test (ISST), a highstakes assessment that students must pass in order to register for their sophomore year. To prepare for the assessment, students work through an online information literacy tutorial, called "Go for the Gold," which has been in existence since the mid-1990s. What was unique about the work of the JMU librarians was their close collaboration with faculty in developing the tutorial and assessment.

On Neyer's recommendation, all the members of our team viewed the tutorial and agreed that we liked what we saw. The tutorial was thorough and had rigorous content, while being succinct and providing visual appeal. We also liked that the tutorial included information about the institution's resources throughout, something that generic tutorials often did not address. JMU stated in their copyright statement that "others may copy and customize the original content and design of "Go for the Gold" for nonprofit educational purposes." So Neyer contacted the librarians at JMU, requesting permission to use and adapt the tutorial, and came up with wording to credit them, which we placed on our tutorial's "start page." The JMU librarians also kindly gave us access to exercises embedded in the tutorial, which they used to give students practice before taking the ISST.

\section{Adapting the tutorial for LibGuides}

Once the team received permission to use the instructional content from "Go for the Gold," the members adapted it for use in LibGuides. ${ }^{2}$ Neyer took the lead, creating the first tutorial module, "Orientation to Andruss Library," and tabs for the remaining seven modules with their corresponding learning objectives. Having the first module as a template made it easy for others on the team to choose a module from "Go for the Gold" and use the "Copy another box from the system" feature in LibGuides to copy portions of Neyer's module. Once copied, each member deleted the content from Neyer's pages and inserted revised content from "Go for the Gold" and from the now-defunct Introduction to Library Research course. This ensured that all tutorial pages were consis- tent - the first page of each module displayed one box with "Learning Objectives" on the left side and a second box that provided links to each page of that module on the right.

One change in "Go for the Gold" that the team made was to use subpages to reduce scrolling. So, although the new tutorial consists of the same number of modules and similar content as the "Go for the Gold" tutorial, it uses more pages. Links were inserted at the bottom of each page to enable easy navigation to the next page, to the previous page, and to the first page of each module. Again, the "Copy another box from the system" feature allowed us to build consistent navigation through the tutorial.

Another departure from "Go for the Gold" came with our decision to create two separate tutorial assessments—one Web-based quiz that provides a means of self-assessment and another that can be imported into Blackboard for faculty who choose to incorporate the tutorial into their courses.

Team members consulted with staff at the university's Instructional Media Design Center, who suggested we use Respondus, a software program that allows the development of exams for importation into Blackboard. Using Respondus made it possible to collaboratively develop a test bank of questions for use in both the Web-based assessment and the Blackboard quizzes. Each team member contributed questions from "their" modules using content from the "Go for the Gold" assessment and from the old Introduction to Library Research course.

Neyer selected questions from the test bank for the 25-item Web-based assessment, which was created using SurveyGizmo, a product designed to create Web-based surveys and assessments. The quiz was embedded in the LibGuides tutorial using Javascript from SurveyGizmo. The second 25 -item assessment was designed to be more rigorous than the first, requiring more application of knowledge. One team member, Kathryn Yelinek, used the remaining questions in the test bank and developed others for the second quiz in Respondus before successfully importing it into a test Blackboard course. Individual faculty members will be able to adapt the quiz as 
needed, including changing the order of the questions, adding or deleting questions, and assigning new point values to questions.

Before announcing the tutorial to the university community prior to the fall semester, Darla Bressler and Kathryn Yelinek rigorously reviewed and polished the tutorial content and the quizzes.

\section{Lessons learned in LibGuides}

Even though LibGuides made it easy to create the tutorial, a few problems emerged during the process. For example, Yelinek ran across an issue of cutting and pasting text that had, apparently, originally been created in a Microsoft Word document. Yelinek had copied text from the "Go for the Gold" tutorial and began to edit it for formatting and content using the LibGuides HTML editor, which automatically generated a large number of odd-looking HTML tags. She contacted the LibGuides support, which quickly responded and informed her that because Microsoft Word documents contain extra formatting information that confuses HTML text editors, LibGuides had developed a special tool for cutting and pasting from Word documents. With this information, she was able to redo her page.

Additionally, because it was so easy to copy in LibGuides, it was also easy to miss changing the many links from boxes copied from the initial module, resulting in pages with incorrect navigational links. As part of the proofreading of the tutorial, Yelinek and Bressler needed to go through the modules page-by-page to standardize the navigation, a tedious but necessary process.

\section{Conclusion}

We hope to assess the impact of the tutorial on our students' information literacy skills with our Information Literacy Assessment, given each year to freshmen and seniors. We are encouraged that more students have taken the 25-item Web-based self-assessment so far this year than took the ten-item assessment last year for the old tutorial. In addition, approximately 15 sections of freshmen students are also taking the Blackboard assessment.

Also encouraging was the response by a number of undergraduate and graduate faculty and administrators to our e-mail announcement. One professor wrote, "This sounds great for some of my other classes as well ... I would like to walk through the tutorial before having the students do so ..." Another wrote, "[T]hanks for this. I will be using parts of it in my Comp II class this term." And another wrote, "I went through the database searching [module] and saw some tips for me too!" By making the tutorial visible and available to everyone on our Web site, classroom faculty can select modules to review basic library research skills with students. And a side benefit is that they become more aware of the library's resources and services, as well.

LibGuides provided the librarians at Bloomsburg University with an easy way to collaborate on the creation of a module-based information literacy tutorial. Its interface allowed for the quick creation of pages, and multiple librarians were able to work together on the project at the same time. Furthermore, the LibGuides tutorial has proven itself easy to update. This ability to share content, including tutorial content, becomes even more crucial as resource sharing becomes the standard in libraries. The University of Texas offers "yourTILT," which enables libraries to selectively download portions of TILT. The trend may also be observed in the cooperation of the JMU librarians with Bloomsburg University librarians. Use of LibGuides may be the next practical extension of this trend, as its pages and content are easy to duplicate and share across institutions.

\section{Notes}

1. Lynn Cameron, Steven L. Wise, and Susan M. Lottridge, "The development and validation of the information literacy test," College E Research Libraries 68, no. 3 (2007):229-36.

2. To view the tutorial, use the links from our blog post on What's New @ Andruss Library, http://andrusslibrarian.blogspot. com/2009_08_01_archive.html. $\boldsymbol{n}$ 